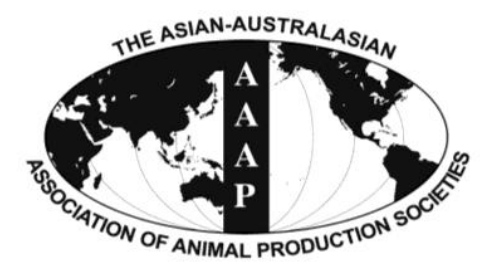

Asian Australas. J. Anim. Sci.

Vol. 26, No. 5 : 661-667 May 2013

http://dx.doi.org/10.5713/ajas.2012.12513

www.ajas.info

pISSN $1011-2367$ elSSN 1976-5517

\title{
Treated Olive Cake as a Non-forage Fiber Source for Growing Awassi Lambs: Effects on Nutrient Intake, Rumen and Urine $\mathrm{pH}$, Performance, and Carcass Yield
}

\author{
M. S. Awawdeh* and B. S. Obeidat ${ }^{1}$ \\ Department of Veterinary Pathology and Public Health, Faculty of Veterinary Medicine, \\ Jordan University of Science and Technology, P.O Box 3030, Irbid 22110, Jordan
}

\begin{abstract}
The objective of this study was to investigate the effects of partial replacement of wheat hay with sun-dried (SOC) or acid-treated SOC (ASOC) olive cake on nutrient intake and performance of Awassi lambs. An additional objective was to study the effects of acid treatment of olive cake (OC) on its chemical composition and nutritive value. On DM basis, sun-drying of OC did not dramatically affect its chemical composition. On the other hand, treating SOC with phosphoric acid decreased ( $\mathrm{p}<0.05)$ SOC contents of neutral detergent fiber. Twenty seven male lambs $(17.6 \pm 0.75 \mathrm{~kg}$ body weight) individually housed in shaded pens were randomly assigned to one of three dietary treatments ( 9 lambs/treatment). Dietary treatments were formulated to be isocaloric and isonitrogenous by replacing $50 \%$ of wheat hay in the control diet (CTL) with SOC or ASOC and to meet all nutrient requirements. Dietary treatments had no effects on nutrient intake or digestibility except for ether extract. Lambs fed the SOC diet had $(p=0.05)$ faster growth rate, greater final body weight, and greater total body weight gain in comparison with the CTL diet, but not different from the ASOC diet. Additionally, lambs fed the SOC diet had greater $(\mathrm{p}=0.03)$ hot and cold carcass weights than the ASOC diet, but not different from the CTL diet. However, feed conversion ratios and dressing percentages were similar among dietary treatments. In conclusion, replacing half of dietary wheat hay with SOC improved performance of Awassi lambs with no detrimental effects on nutrients intake or digestibility. No further improvements in the nutritive value of SOC and lambs performance were detected when SOC was treated with acid. (Key Words: Alternative Feed, Olive Cake, Performance, Carcass Yield, Sheep)
\end{abstract}

\section{INTRODUCTION}

Mediterranean countries provide about $98 \%$ of the world's total olive-oil production (International Olive Oil Council Statistics, 2011). Only 20 to $27 \%$ of the processed olive fruit ends up as oil and the balance as byproducts. One of the major byproducts is olive cake (OC; the residue obtained after pressure extraction of oil from entire olive fruit and contains skin, crushed pulp, stone wall, and kernel). Jordan is the 6th largest producer of olive oil in the world with average of 22,800 tons/yr; along with that, 62,700 tons/yr of OC is annually produced (International Olive Oil Council Statistics, 2011). Although these

\footnotetext{
* Corresponding Author: M. S. Awawdeh. Tel: +962-2-7201000, Fax: +962-2-7201081, E-mail: mawawdeh@ just.edu.jo

1 Department of Animal Production, Faculty of Agriculture, Jordan University of Science and Technology, P.O Box 3030, Irbid 22110, Jordan.

Submitted Sept. 18, 2012; Accepted Dec. 20, 2012; Revised Dec. 26, 2012
}

byproducts have been successfully utilized in ruminant feeding (Molina-Alcaide and Nefzaoui, 1996), biogas production (Al-Masri, 2001), and paper industry (Jiménez et al., 1999), some byproducts are unnecessarily disposed off into the environment. These byproducts do not easily decompose over a long period of time (years) and still present economical (getting rid of these wastes) and environmental problems (Molina-Alcaide and Yáñez-Ruiz, 2008).

Olive cake is usually described as low-quality feedstuff because of the high contents of ligno-cellulotic materials and low contents of protein and energy (Al-Masri and Guenther, 1995; Molina-Alcaide and Nefzaoui, 1996; Abbeddou et al., 2011). Different approaches to improve the nutritive value of OC have been tested. De-stoning (manual removal of crushed seeds), ensiling (Hadjipanayiotou, 1994; Al Jassim et al., 1997; Abo Omar et al., 2012), pelleting (Abo Omar et al., 2012), and exogenous fibrolytic enzymes (Awawdeh and Obeidat, 2011) have been 
investigated. Chemical treatment of OC with alkali or oxidizing compounds (i.e., $\mathrm{NaOH}$ and anhydrous ammonia) is another approach. However, soap may be formed by treating oil-rich OC with alkali (Molina-Alcaide and YáñezRuiz, 2008). Thus, treating OC with different chemicals (i.e., inorganic acids) may worth investigation because acid can decrease NDF contents of OC (Table 1), expose cellulose to ruminal microbes, and it is used as a flavoring agent in food industry (Russell and Gould, 2003) which could improve animal preference to this feedstuff. Although uncertain, it has been suggested that sour and umami tastes (probably, as those induced by phosphoric acid in ASOC diet) can enhance intake and preference in sheep (Ginane et al., 2011).

Using local agro-industrial byproducts in feeding livestock animals, like OC, will provide a cheap and environment-friendly alternative feedstuff (Awawdeh, 2011). The objectives of the current study were to study the effects of: i) acid treatment of SOC on its chemical composition and nutritive value and ii) partial replacement of wheat hay in concentrate-based diets with sun-dried (SOC) or acidtreated (ASOC) OC on nutrients intake, rumen and urine $\mathrm{pH}$, performance, and carcass yield of male Awassi lambs. We hypothesized that SOC can successfully be used as a non-forage fiber source for Awassi lambs and that acid treatment of SOC might improve its nutritive value.

\section{MATERIAL AND METHODS}

This study was conducted at the Agriculture Center for Research and Production at Jordan University of Science and Technology (JUST). The JUST Institutional Animal Care and Use Committee approved all procedures used in this study.

\section{Obtaining OC}

About 5 months before starting the fattening study, OC was obtained from a single local olive oil-extraction mill

Table 1. Effects of sun-drying or acid treatment of olive cake on its chemical composition (\% of DM basis)

\begin{tabular}{lcccc}
\hline \multirow{2}{*}{ Item } & \multicolumn{3}{c}{ Olive cake $^{1}$} & \multirow{2}{*}{ SEM } \\
\cline { 2 - 4 } & Fresh OC & SOC & ASOC & \\
\hline $\mathrm{n}$ & 5 & 5 & 5 & \\
Nutrient & & & & \\
$\quad$ Dry matter & $51.5^{\mathrm{c}}$ & $92.5^{\mathrm{a}}$ & $64.3^{\mathrm{b}}$ & 0.13 \\
$\quad$ Organic matter & $95.3^{\mathrm{a}}$ & $92.5^{\mathrm{b}}$ & $72.0^{\mathrm{c}}$ & 0.30 \\
$\quad$ Crude protein & 6.6 & 8.3 & 6.8 & 0.52 \\
$\quad$ Neutral detergent fiber & $54.1^{\mathrm{a}}$ & $53.3^{\mathrm{a}}$ & $41.7^{\mathrm{b}}$ & 0.60 \\
$\quad$ Acid detergent fiber & $37.1^{\mathrm{a}}$ & $34.5^{\mathrm{b}}$ & $33.6^{\mathrm{b}}$ & 0.70 \\
$\quad$ Ether extract & 22.7 & 22.9 & 23.4 & 0.42 \\
Gross energy (Mcal/kg) & 6.6 & 6.5 & 6.4 & 0.12 \\
\hline
\end{tabular}

${ }_{\mathrm{a}, \mathrm{b}, \mathrm{c}}$ Within row, means with different superscript are different at $\mathrm{p}<0.05$. ${ }^{1} \mathrm{SOC}=$ Sun-dried OC and ASOC $=$ Acid-treated SOC. Please refer to text for further details. (utilizing three-phase centrifugation extraction procedure). To obtain SOC, OC was sun-dried upon reception by spreading it into a thin layer $(5 \mathrm{~cm})$ on plastic sheets for about 2 months. During these 2 months, average drying conditions were as follows: temperature 15 to $25^{\circ} \mathrm{C}$, relative humidity 50 to $65 \%$, and daylight 7 to $9 \mathrm{~h}$. Weekly, spread OC was manually turned over, mixed, and re-spread to prevent spoilage. After drying, SOC was stored in plastic bags to be used in making dietary treatments and to obtain ASOC. Acid-treated SOC was prepared by mixing 10 parts (weight basis) of SOC with one part of concentrated (85\%) feed-grade phosphoric acid in metal containers and stored in plastic bags. Representative samples of OC were obtained at the time of receiving (fresh OC), after sun-drying (SOC), and about three months after acid treatments of SOC (ASOC). Samples were ground (1-mm screen) and stored $\left(-20^{\circ} \mathrm{C}\right)$ for future analysis.

\section{Animals, design, and dietary treatments}

A fattening study was initiated about 3 months after making the ASOC. Intact male Awassi lambs raised at the Agriculture Center of JUST weaned at age of 65 to $70 \mathrm{~d}$ were used. Twenty seven lambs (initial body weight \pm SEM $17.6 \pm 0.75 \mathrm{~kg})$ individually housed in shaded pens $(1.5$ $\mathrm{m} \times 0.75 \mathrm{~m}$ ) were randomly assigned to one of three dietary treatments (9 lambs/treatment) according to a completelyrandomized design. Initial $\mathrm{BW}$ was considered in randomization. One week before commencement the study, lambs were treated for internal (Albendazole; AVICO, Amman, Jordan) and external (Ivermectin; AVICO, Amman, Jordan) parasites, gradually introduced to dietary treatments, and adapted for individual pens. The study started about one week after weaning and lasted for 68 days.

Dietary treatments were formulated by replacing $50 \%$ (fresh basis) of wheat hay in the control diet (CTL) with SOC (SOC) or ASOC (ASOC). Wheat hay was the selected ingredient to be replaced because chemical composition of $\mathrm{OC}$ (i.e., NDF and ADF) is comparable to low quality cereal straws (Table 1). Thus, it would be more appropriate to include $\mathrm{OC}$ in ruminant diets by replacing low-quality feedstuffs (i.e., roughage) rather than by replacing energy or protein sources as was carried out by others (Aguilera et al., 1992; Al Jassim et al., 1997). Diets were formulated to be isocaloric and isonitrogenous and to meet all nutrient requirements for lambs (NRC, 1985). Sodium bicarbonate was added as a buffer to prevent ruminal acidosis that might be induced by acid included in ASOC. Diets were mixed biweekly and upon mixing, samples of dietary ingredients (barley, soybean, wheat hay, wheat bran, SOC, and ASOC) were collected, ground, and saved $\left(-20^{\circ} \mathrm{C}\right)$ for future analysis.

Diets were offered, as total mixed ration (TMR), once a 
day at $0800 \mathrm{~h}$ and lambs had free access to clean water throughout the study. The amount of TMR offered and refused was recorded daily for each lamb and was adjusted to ensure ad libitum consumption. For each lamb, samples of refused feed were collected daily, composited at the end of the feeding experiment, and stored $\left(-20^{\circ} \mathrm{C}\right)$ for later analysis.

At the beginning and, on weekly basis throughout the study, lambs were weighed before the morning feeding. Lambs average daily gain (ADG) was calculated by subtracting initial from final BW and then dividing by the duration of study. Upon conclusion of the study, blood $\mathrm{pH}$ was immediately measured (Laboratory $\mathrm{pH}$ meter, Hanna instruments Inc., RI, USA) in blood samples obtained from the jugular vein into vacuum tubes (containing sodium heparin) before the morning feeding.

\section{Digestibility and $\mathbf{N}$ balance}

During the last two weeks of the fattening study, six lambs from each treatment group were randomly selected and placed in metabolism crates $(105 \times 80 \mathrm{~cm})$ designed for separate collection of feces and urine to measure nutrient digestibilities and $\mathrm{N}$ balance. Because lambs were already adapted to dietary treatments, they were given only $3 \mathrm{~d}$ to adapt to crates followed by $4 \mathrm{~d}$ for sample collection. Samples of offered and refused feed were collected, composited, ground (1-mm screen) and stored $\left(-20^{\circ} \mathrm{C}\right)$ for later analyses. Feces were collected in plastic buckets, weighed, sampled (10\%), composited, dried (at $55^{\circ} \mathrm{C}$ for 48 $\mathrm{h}$ to reach a constant weight and then air-equilibrated), ground, and then stored for later analysis. Urine was collected in plastic buckets containing $50 \mathrm{ml}$ of $1 \mathrm{~N} \mathrm{HCl}$. Urine was weighed, sampled $(5 \%)$, and stored $\left(-20^{\circ} \mathrm{C}\right)$ for later analysis of $\mathrm{N}$ to calculate $\mathrm{N}$ retention as amount and as a percent of intake N. Feed, feces, and urine samples were separately collected for each lamb. At the end of the digestibility trial, lambs were maintained in crates for an additional day and urine was collected in blank buckets (without $\mathrm{HCl}$ ) to measure urine $\mathrm{pH}$.

Upon conclusion of the study, all lambs were slaughtered according to the standard procedure described by Abdullah et al. (1998), without fasting. Upon slaughtering, hot-carcass weights were immediately measured. Upon dressing, samples of rumen fluid were obtained and $\mathrm{pH}$ was immediately measured. Carcasses were chilled at $4{ }^{\circ} \mathrm{C}$ for $24 \mathrm{~h}$ and then cold carcass weights were recorded. Dressing percentage was calculated as the hot-carcass weight percentage of the final live weight.

\section{Analytical methods}

Obtained samples of OC (fresh, SOC, ASOC), dietary ingredients, and refused feed were analyzed according to procedures of AOAC (1990) for dry matter (DM; $105^{\circ} \mathrm{C}$ in a forced-air oven for $24 \mathrm{~h}$; method 967.03), organic matter $\left(\mathrm{OM}\right.$; weight loss upon ashing at $550^{\circ} \mathrm{C}$ for $8 \mathrm{~h}$; method 942.05), nitrogen (N; Kjeldahl procedure; method 976.06), ether extract (EE; Soxhlet procedure, Soxtec System HT 1043 Exctraxtion Unit, TECATOR, Hoganas, Sweden; method 920.29), and gross energy (GE; automatic adiabatic bomb calorimeter, Sanyo Gallenkamp PLC, Leicester, UK). Neutral detergent fiber (NDF; with heat stable $\alpha$-amylase and $\mathrm{Na}$ sulfite) and acid detergent fiber (ADF) were determined according to Van Soest et al. (1991) using ANKOM $^{2000}$ fiber analyzer (ANKOM Technology Corp., Fairport, NY). Values for NDF and ADF were not corrected for ash contents. Diet $\mathrm{pH}$ was measured after blending $10 \mathrm{~g}$ of the diet with $100 \mathrm{ml}$ of distilled water for $2 \mathrm{~min}$ (Arbabi and Ghoorchi, 2008).

Samples of the offered and refused feed and dried feces from digestibility study were analyzed for DM, OM, N, $\mathrm{NDF}$, and ADF to calculate nutrient digestibility. Urine samples were analyzed for $\mathrm{N}$ content.

\section{Statistical analysis}

All data were analyzed statistically using the Mixed procedure of SAS (2002) for Windows Release 9.0 (SAS Inst. Inc., Cary, NC, USA) as a completely-randomized design and lamb was included as a random variable. For the performance data, initial $\mathrm{BW}$ of lambs was included as a covariate. Treatment means were computed using the LSMEANS option and separated using preplanned pairwise comparisons of least squares means using t-tests. Treatment effects were considered significant at $\mathrm{p}<0.05$.

\section{RESULTS}

Effect of sun drying or acid treatment on OC composition and treatment diets

Effects of sun-drying or acid treatment of OC on its chemical composition are presented on Table 1. On DM basis, SOC contained comparable contents of CP, NDF, EE, and GE and slightly less ADF compared with those of fresh OC. Thus, it appears that sun-drying of OC did not dramatically affect its chemical composition. On the other hand, treating SOC (sun-cured) with phosphoric acid decreased $(\mathrm{p}<0.05)$ SOC contents of NDF with minimal effects on $\mathrm{CP}, \mathrm{ADF}, \mathrm{EE}$, or GE contents.

Ingredient and chemical composition of dietary treatments are presented in Table 2. Both SOC and ASOC diets contained relatively similar contents of $\mathrm{CP}, \mathrm{NDF}, \mathrm{ADF}$, and metabolizable energy (ME) but higher EE contents when compared to the CTL diet. The $\mathrm{pH}$ of ASOC diet was slightly acidic (5.8) compared to the CTL or SOC diets (6.6), as a result of acid treatment. The cost (US \$) of making one ton was least for the SOC (341), intermediate 
Table 2. Ingredient and chemical composition (\% of DM) of dietary treatments

\begin{tabular}{lccc}
\hline \multirow{2}{*}{ Item } & \multicolumn{3}{c}{ Treatment $^{1}$} \\
\cline { 2 - 4 } & CTL & SOC & ASOC \\
\hline Ingredient & 51.5 & 51.5 & 53.1 \\
Barley & 20.2 & 10.1 & 10.4 \\
Wheat hay & 9.8 & 9.8 & 10.2 \\
Wheat bran & 14.9 & 14.9 & 15.4 \\
Soybean meal & 0 & 10.1 & 0 \\
SOC & 0 & 0 & 7.3 \\
ASOC & 1.1 & 1.1 & 1.1 \\
Limestone & 1.1 & 1.1 & 1.1 \\
Salt & 1.1 & 1.1 & 1.1 \\
Na Bicarbonate & 0.2 & 0.2 & 0.2 \\
Vitamin/minerals premix ${ }^{2}$ & & & \\
Nutrient & 91.4 & 91.6 & 89.5 \\
Dry matter & 90.0 & 91.2 & 89.0 \\
Organic matter & 17.1 & 17.6 & 17.8 \\
Crude protein & 31.9 & 29.7 & 27.9 \\
Neutral detergent fiber & 12.9 & 12.2 & 11.3 \\
Acid detergent fiber & 1.4 & 3.7 & 3.3 \\
Ether extract & 2.33 & 2.29 & 2.32 \\
Metabolizable energy $(\mathrm{Mcal} / \mathrm{kg})^{3}$ & 6.66 & 6.64 & 5.85 \\
pH & 369 & 341 & 350 \\
Cost (US \$/ton as fed) & 4 & & \\
\hline
\end{tabular}

${ }^{1} \mathrm{CTL}=$ Control (no OC), SOC $=$ Sun-dried OC replaced half of wheat hay in the CTL diet, ASOC = Acid-treated SOC replaced half of wheat hay in the CTL diet. Please refer to text for further details.

${ }^{2}$ Composition per $1 \mathrm{~kg}$ contained (vitamin A, 2,000,000 IU; vitamin $\mathrm{D}_{3}$, 400,00 IU; vitamin E, $400 \mathrm{mg}, \mathrm{Mn}, 12.80 \mathrm{~g}$; Zn, $9.00 \mathrm{~g}$; I, $1.56 \mathrm{~g} ; \mathrm{Fe}$, $6.42 \mathrm{~g} ; \mathrm{Cu}, 1.60 \mathrm{~g}$; Co, $50 \mathrm{mg}$; Se, $32 \mathrm{mg}$ plus antioxidant).

${ }^{3}$ Metabolizable energy; based on tabular values (NRC, 1985). ME contents of SOC and ASOC was estimated using published values for crude OC (Morgan and Trinder 1980; Aguilera and Molina 186; Al Jassim et al., 1997).

${ }^{4}$ Calculated based on ingredient prices at the time of writing the manuscript.

for the ASOC (350), and highest for the CTL (369).

\section{Intake, digestibility, and lamb performance}

Weight gain and nutrient intake data of lambs are listed in Table 3. There were no effects $(p \geq 0.19)$ of dietary treatments on lambs' intake of DM, OM, CP, NDF, or ADF. Ether extract intake was greatest for lambs offered the SOC diet (i.e., $35 \mathrm{~g} / \mathrm{d}$ ), intermediate for those offered the ASOC diet (i.e., $25 \mathrm{~g} / \mathrm{d}$ ), and least (i.e., $12 \mathrm{~g} / \mathrm{d}$ ) for those offered the CTL diet $(p<0.05)$ as a reflection of EE contents in those diets (Table 2). Lambs fed the SOC diet had ( $\mathrm{p}=$ 0.05 ) faster growth rate, greater final $\mathrm{BW}$, and greater total BW gain in comparison with the CTL diet, but not different $(\mathrm{p}=0.62)$ from the ASOC diet. Additionally, lambs that consumed the SOC diet had $(\mathrm{p}=0.03)$ greater hot and cold carcass weights than the ASOC diet, but not different $(\mathrm{p} \geq 0.24)$ from the CTL diet. However, feed conversion ratios and dressing percentages were not affected ( $\mathrm{p} \geq 0.12$ ) by dietary treatments. The estimated cost of gain (US $\$ / \mathrm{kg}$ ) for the CTL, SOC, ASOC diets were about 1.96, 1.69, and 1.62 , respectively.

Digestibility of DM, OM, CP, NDF, and ADF were not affected $(\mathrm{p} \geq 0.63)$ by dietary treatments (Table 4). Additionally, $\mathrm{N}$ intake and $\mathrm{N}$ excreted in feces and urine were not affected $(\mathrm{p} \geq 0.13)$ by dietary treatments. Consequently, retained $\mathrm{N}$ as amount or as percent of intake $\mathrm{N}$ were similar $(\mathrm{p} \geq 0.15)$ across dietary treatments.

Because ASOC diet was more acidic than the CTL and SOC diets (Table 2), we expected that feeding this diet to lambs could affect the $\mathrm{pH}$ values of rumen fluid, urine, and blood. Dietary treatments had no effects $(\mathrm{p}=0.24)$ on ruminal $\mathrm{pH}(6.2,5.94,6.09$ for CTL, SOC, and ASOC, respectively). Feeding lambs with diets containing SOC resulted in a slight increase $(\mathrm{p}<0.05)$ in blood $\mathrm{pH}(7.52)$ compared to the CTL (7.46) and ASOC (7.54) diets. Lambs fed the ASOC diet produced $(\mathrm{p}<0.05)$ acidic urine $(\mathrm{pH}=$ 6.91) compared to the CTL (8.38) or SOC (8.25) diets, which may have resulted from slightly acidic diet (Table 2).

\section{DISCUSSION}

\section{Effect of sun drying or acid treatment on OC composition}

Chemical compositions of fresh OC, SOC, and ASOC in the present study were in the range of previously reported values (Molina-Alcaide and Nefzaoui, 1996; MolinaAlcaide et al., 2003; Molina-Alcaide and Yáñez-Ruiz, 2008). The current study is the first to report the effect of treating OC with phosphoric acid on its chemical composition and nutritive value. Thus, treating SOC with phosphoric acid deserved our investigation.

Treating SOC with acid decreased its NDF contents probably due to breaking off cross linkages between lignin and cell wall components and solubilizing cell wall contents (mainly hemicellulose). Phosphoric acid is used as preservative, flavoring agent (Russell and Gould, 2003), or as acidifying agent in animal feed (Izquierdo and Czarnecki-Maulden, 1991). Furthermore, Abo Omar et al. (2012) demonstrated no added advantage of alkalinetreatment or ensiling (common methods to improve the nutritive value) of OC as compared with untreated-OC in feeding growing Awassi lambs. Thus, investigating other methods to improve the nutritive value of olive cake is needed.

\section{Intake, digestibility, and lamb performance}

Similar to our results, replacing barley in the basal diet with urea-treated OC (from 0 to $30 \%$ ) had no effects on final $\mathrm{BW}, \mathrm{ADG}$, or feed conversion ratio of growing Awassi lambs (Al Jassim et al., 1997). Abo Omar et al. (2012) 
Table 3. Weight gain and nutrient intake of male Awassi lambs fed differently-treated olive cake

\begin{tabular}{|c|c|c|c|c|c|}
\hline \multirow{2}{*}{ Item } & \multicolumn{3}{|c|}{ Dietary treatment $^{1}$} & \multirow{2}{*}{ SEM } & \multirow{2}{*}{ p-value } \\
\hline & CTL & SOC & ASOC & & \\
\hline$\overline{\mathrm{n}}$ & 9 & 9 & 9 & & \\
\hline Initial body weight $(\mathrm{kg})$ & 17.7 & 17.7 & 17.4 & 0.75 & 0.96 \\
\hline Final body weight (kg) & $30.7^{\mathrm{b}}$ & $34.4^{\mathrm{a}}$ & $33.6^{\mathrm{a}, \mathrm{b}}$ & 2.29 & 0.07 \\
\hline Total gain $(\mathrm{kg})$ & $13.1^{\mathrm{b}}$ & $16.8^{\mathrm{a}}$ & $16.0^{\mathrm{a}, \mathrm{b}}$ & 2.29 & 0.07 \\
\hline Average daily gain $(\mathrm{g} / \mathrm{d})$ & $192^{\mathrm{b}}$ & $247^{\mathrm{a}}$ & $234^{a, b}$ & 33.7 & 0.07 \\
\hline Hot carcass weight $(\mathrm{kg})$ & $14.4^{\mathrm{a}, \mathrm{b}}$ & $15.0^{\mathrm{a}}$ & $13.3^{\mathrm{b}}$ & 0.48 & 0.07 \\
\hline Cold carcass weight $(\mathrm{kg})$ & $13.9^{\mathrm{a}, \mathrm{b}}$ & $14.7^{\mathrm{a}}$ & $13.1^{\mathrm{b}}$ & 0.47 & 0.08 \\
\hline \multicolumn{6}{|l|}{ Nutrient intake $(\mathrm{g} / \mathrm{d})$} \\
\hline Dry matter & 1,024 & 1,228 & 1,086 & 178.0 & 0.26 \\
\hline Organic matter & 925 & 1116 & 962 & 151.9 & 0.19 \\
\hline Crude protein & 150 & 201 & 196 & 40.8 & 0.29 \\
\hline Ether extract & $12^{\mathrm{c}}$ & $35^{\mathrm{a}}$ & $25^{\mathrm{b}}$ & 3.0 & $<0.05$ \\
\hline Neutral detergent fiber & 279 & 336 & 304 & 65.4 & 0.39 \\
\hline Acid detergent fiber & 112 & 134 & 119 & 26.7 & 0.39 \\
\hline Feed conversion ratio ${ }^{2}$ & 5.7 & 5.5 & 5.4 & 0.41 & 0.91 \\
\hline Dressing percentage $^{3}$ & 47.8 & 46.1 & 43.2 & 1.83 & 0.12 \\
\hline
\end{tabular}

${ }^{a, b, c}$ Within row, means with different superscript are different at $\mathrm{p}<0.05$.

${ }^{1} \mathrm{CTL}=\mathrm{Control}($ no OC), SOC $=$ Sun-dried OC replaced half of wheat hay in the CTL diet, ASOC = Acid-treated SOC replaced half of wheat hay in the CTL diet. Please refer to text for further details.

${ }^{2}$ Feed conversion ratio $=\mathrm{DM}$ intake/ADG. ${ }^{3}$ Calculated as the hot-carcass weight proportion of final BW.

concluded that $15 \%$ inclusion of different forms of OC (crude, alkali-treated, or ensiled) had no adverse effect on performance and carcass characteristics of Awassi lambs. It would be more beneficial to include OC at low levels $(<30 \%)$ in animal diets because higher levels could limit the availability of other nutrients (i.e., ruminally degradable N) and increase lignin load. For example, when OC was included at low levels (13\% of DM) in diets for sheep and goats, Yáñez-Ruiz et al. (2004) observed no effects on feed intake. Additionally, dietary inclusion of fermented olive-

Table 4. Nutrient digestibilities and nitrogen balance of male Awassi lambs fed differently-treated olive cake

\begin{tabular}{lrrrrr}
\hline \multirow{2}{*}{ Item } & \multicolumn{3}{c}{ Dietary treatment } & \multirow{2}{*}{ SEM } & \multirow{2}{*}{ p-value } \\
\cline { 2 - 4 } & CTL & SOC & ASOC & & \\
\hline $\mathrm{n}$ & 6 & 6 & 6 & & \\
Digestibility (\%) & & & & & \\
Dry matter & 77.6 & 76.2 & 77.1 & 2.19 & 0.91 \\
Organic matter & 80.7 & 78.4 & 78.5 & 2.02 & 0.76 \\
Crude protein & 78.2 & 76.0 & 75.9 & 2.16 & 0.71 \\
Neutral detergent fiber & 60.4 & 55.8 & 58.1 & 4.27 & 0.74 \\
Acid detergent fiber & 51.4 & 48.6 & 45.0 & 4.71 & 0.63 \\
Nitrogen & & & & & \\
$\quad$ Intake (g/d) & 39.2 & 34.4 & 33.3 & 2.06 & 0.13 \\
$\quad$ Fecal (g/d) & 8.6 & 8.2 & 8.0 & 0.95 & 0.89 \\
$\quad$ Urinary (g/d) & 8.4 & 8.9 & 7.8 & 1.10 & 0.81 \\
$\quad$ Retained (g/d) & 22.1 & 17.2 & 17.2 & 1.89 & 0.15 \\
$\quad$ Retained (\%of N intake) & 56.8 & 50.0 & 52.1 & 4.30 & 0.53 \\
\hline
\end{tabular}

${ }^{1} \mathrm{CTL}=$ Control (no OC), SOC $=$ Sun-dried OC replaced half of wheat hay in the CTL diet, ASOC = Acid-treated SOC replaced half of wheat hay in the CTL diet. Please refer to text for further details. wastes lower in nutritive value (higher NDF and ADF) than the one used in the current study had no negative effects on intake, $\mathrm{ADG}$, final $\mathrm{BW}$, feed conversion ratio, carcass weights, or components for Florina lambs when included at moderate (0 to 15\%) levels (Christodoulou et al., 2008).

Another point that needs to be considered in using low quality byproducts is that the experimental diets should be isocaloric and isonitrogenous to the control diet. As evidence, when OC replaced an increasing percentage of concentrate mixture (0 to $50 \%$ ) in lamb diet, there were no differences in daily gain or dressing percentage when all diets were isonitrogenous (Razzaque et al., 1980). Furthermore, when diets were balanced for protein and energy contents, partial or complete replacement of wheat bran $(20 \%$ of diet DM) or $25 \%$ replacement of barley $(40 \%$ of diet DM) with olive pulp did not affect intake, milk yield, or composition of dairy cows (Belibasakis, 1984). Dietary inclusion (by replacing beet pulp and alfalfa meal) of OC at $20 \%$ in isonitrogenous diets (by increasing soybean meal) actually improved milk yield of ewes (Chiofalo et al., 2004).

Thus, it appears that our dietary treatments (particularly SOC) improved the performance of lambs because OC was included at moderate levels (at 10\%, fresh basis) and all treatment diets were isocaloric and isonitrogenous. Additionally, SOC might have shifted the digestibility of nutrients (without affecting total tract digestibility) to the hindgut and improved microbial protein synthesis in the rumen (Firkins, 1997) and, subsequently, improved our lambs' performance. Furthermore, greater EE intake by lambs receiving the SOC than the ASOC or the CTL diets 
might have contributed to improved performance observed in lambs consuming the SOC diet. This demonstrates that OC had a higher nutritive value, in terms of animal performance, compared to wheat hay or ASOC as a nonforage fiber source.

It is known that nutrient digestibilities of OC are low and variable (Molina-Alcaide and Yáñez-Ruiz, 2008). It has been reported that $\mathrm{DM}$, fiber, and $\mathrm{CP}$ digestibilities were low and fat digestibility was high (Molina-Alcaide and Nefzaoui, 1996). It is difficult and probably inappropriate to compare "specific" values of nutrient digestibility from previous studies with our values due to inherent differences among studies in term of experimental settings (basal diet and level of intake), type and level of tested OC, and techniques for estimating digestibility. In contrast to our results, Al Jassim et al. (1997) reported that replacing barley with urea-treated OC (from 0 to $30 \%$ ) progressively depressed the digestibility of DM, OM, NDF, and ADF in Awassi lambs with no substantial effects on $\mathrm{CP}$ digestibility. However, after a careful observation of the previous study (Al Jassim et al., 1997) it is clear that the negative effect of OC on nutrient digestibility varied among inclusion levels (10 vs 30\%). For example, OC inclusion at 30\%, but not $10 \%$, dramatically depressed digestibilities of NDF and ADF. In fact, the $10 \%$ inclusion increased NDF digestibility, emphasizing the advantage of using OC at moderate levels as stated earlier.

Our results, that inclusion of OC did not affect ruminal $\mathrm{pH}$, were similar to those of Molina-Alcaide and Nefzaoui (1996) who indicated that feeding OC to sheep resulted in favorable $\mathrm{pH}$ of fibrolytic activity (6.6 to 7.2). However, dietary inclusion of two-stage dried OC (13\% of DM) decreased ruminal pH in sheep (Yáñez-Ruiz et al., 2004). Two-stage OC contains both OC and vegetative water and it is known that vegetative water has a high content of phenolic acids. Thus, OC in the study of Yáñez-Ruiz et al. (2004) contained higher contents of phenolic acids than that of three-stage OC (the one used in the current study), resulting into the observed drops in ruminal $\mathrm{pH}$. In contrast, when de-stoned (removal of crushed seeds from OC) extracted (after fat extraction) OC was fed to sheep (level unmentioned) it increased ruminal $\mathrm{pH}$ (Nefzaoui and Vanbelle, 1986).

The fact that dietary inclusion of ASOC produced slightly-acidic urine can be further investigated as a mean to prevent phosphatic urinary calculi in feedlot animals. It is known that formation of phosphatic urinary urolithiasis increased in alkaline, as opposed to acidic, urine (Hoar et al., 1969).

\section{CONCLUSIONS AND IMPLICATIONS}

In conditions similar to the current study, sun-dried olive cake can be used as an inexpensive non-forage fiber source in sheep diets with better nutritive value than wheat hay. Sheep producers are encouraged to replace half of wheat hay with sun-dried olive cake in diets (similar to the one used in this study) for Awassi lambs. Such technique will improve lamb performance and, subsequently, reduce production cost with no detrimental effects on nutrient digestibility or carcass yield. Treating sun-dried olive cake with acid did not further improve lamb performance and, thus, it is not a recommended method to improve the nutritive value of olive cake. Future research should concentrate on finding other methods to improve the nutritive value of olive cake.

\section{ACKNOWLEDGEMENTS}

The author would like to thank the Deanship of Scientific Research at Jordan University of Science and Technology for funding this project (\#118/2007). The help of staff of Agricultural Center for Research and Production at JUST is highly appreciated. Special thanks are due to Miss. B. Talafha and Mrs. F. Khanfar for their help in laboratory work.

\section{REFERENCES}

Abbeddou, S., S. Riwahi, L. Iñiguez, M. Zaklouta, H. D. Hess and M. Kreuzer. 2011. Ruminal degradability, digestibility, energy content, and influence on nitrogen turnover of various Mediterranean by-products in fat-tailed Awassi sheep. Anim. Feed Sci. Technol. 163:99-110.

Abdullah, A. Y., R. W. Purchas and A. S. Davies. 1998. Patterns of change with growth for muscularity and other composition characteristics of Southdown rams selected for high and low back fat depth. NZ. J. Agric. Res. 41:367-376.

Abo Omar, J. M., R. Daya and A. Ghaleb. 2012. Effects of different forms of olive cake on the performance and carcass quality of Awassi lambs. Anim. Feed Sci. Technol. 171:167172.

Aguilera, J. F., M. A. García and E. Molina. 1992. The performance of ewes offered concentrates containing olive byproducts in late pregnancy and lactation. Anim. Prod. 55:219226.

Al Jassim, R. A. M., F. T. Awadeh and A. Abodabos. 1997. Supplementary feeding value of urea-treated olive cake when fed to growing Awassi lambs. Anim. Feed Sci. Technol. 64:287-292.

Al-Masri, M. R. and K. D. Guenther. 1995. The effect of gamma irradiation on in vitro digestible energy of some agricultural residues. Wirtschaftseigene Futter. 41:61-68.

Al-Masri, M. R. 2001. Changes in biogas production due to different ratios of animal and agricultural wastes. Bioresour. Technol. 77:97-100.

AOAC. 1990. Official Methods of Analysis, 15th edn. Association of Official Analytical Chemists, Arlington, Virginia, USA.

Arbabi, S. and T. Ghoorchi. 2008. The effects of different levels of 
molasses as silage additives on fermentation quality of fox millet (Setariaitalic) silage. J. Agric. Sci. Nat. Res. 16:99-108.

Awawdeh, M. S. 2011. Alternative feedstuffs and their effects on performance of Awassi sheep: a review. Trop. Anim. Health Prod. 43:1297-1309.

Awawdeh, M. S. and B. S. Obeidat. 2011. Effect of supplemental exogenous enzymes on performance of finishing Awassi lambs fed olive cake-containing diets. Livest. Sci. 138:20-24.

Belibasakis, N. G. 1984. The effect of olive cake pulp in milk yield composition in the cow. World Rev. Anim. Prod. 20:67-70.

Ginane, C., R. Baumont and A. Favreau-Peigné. 2011. Perception and hedonic value of basic tastes in domestic ruminants. Physiol. Behav. 104:666-674.

Chiofalo, B., L. Liotta, A. Zumbo and V. Chiofalo. 2004 Administration of olive cake for ewe feeding: effect on milk yield and composition. Small Rumin. Res. 55:169-176.

Christodoulou, V., V. A. Bampidis, C. J. Israilides, P. H. Robinson, A. Giouzelyiannis and A. Vlyssides. 2008. Nutritional value of fermented olive wastes in growing lamb rations. Anim. Feed Sci. Technol. 141:375-383.

Firkins, J. L. 1997. Effects of feeding nonforage fiber sources on site of fiber digestion. J. Dairy Sci. 80:1426-1437.

Hadjipanayiotou, M. 1994. Laboratory evaluation of ensiled olive cake, tomato pulp and poultry litter. Livest. Res. Rural Dev. 6:1-7.

Hoar, D. W., R. J. Emerick and L. B. Embry. 1969. Ovine phosphatic urolithiasis as related to phosphorus and calcium contents and acid-base-forming effect of all-concentrate diets. J. Anim. Sci. 29:647-652.

International olive oil council. 2011. http://www. internationaloliveoil.org

Izquierdo, J. V. and G. L. Czarnecki-Maulden. 1991. Effect of various acidifying agents on urine $\mathrm{pH}$ and acid-base balance in adult cats. J. Nutr. 121:S89-S90.
Jiménez, L., I. Pérez, M. J. de la Torre and J. C. Gracía. 1999. The effect of processing variables on soda pulping of olive tree wood. Biores. Technol. 69:95-102.

Molina-Alcaide, E. and A. Nefzaoui. 1996. Recycling of olive oil by-products: possibilities of utilization in animal nutrition. Int. Biodeterior. Biodegrad. 38:227-235.

Molina-Alcaide, E. and D. R. Yáñez-Ruiz. 2008. Potential use of olive by-products in ruminant feeding: A review. Anim. Feed Sci. Technol. 147:247-264.

Molina-Alcaide, E., D. R. Yáñez-Ruiz, A. Moumen and A. I. Martín García. 2003. Chemical composition and nitrogen availability for goats and sheep of some olive by-products. Small Rumin. Res. 49:329-336.

Nefzaoui, A. and M. Vanbelle. 1986. Effects of feeding alkalitreated olive cake on intake, digestibility and rumen liquor parameters. Anim. Feed Sci. Technol. 14:139-149.

National Research Council. 1985. Nutrient Requirement of Sheep. $6^{\text {th }}$ Ed. National Academy Press, Washington, DC, USA.

Razzaque, M. A., A. M. Aboaysha and F. E. Omar. 1980. Olive oil cake as feed for barbari lambs. Proc. Nutr. Soc. 39:34A.

Russell, N. J. and G. W. Gould. 2003. Food Preservatives. $2^{\text {nd }}$ edn. Kluwer Academic/Plenum Publishers, NewYork, USA.

SAS Institute Inc. 2002. SAS User's Guide: Statistics. SAS Institute Inc., Cary, North Carolina, USA.

Van Soest, P. J., J. B. Robertson and B. A. Lewis. 1991. Methods for dietary fiber, neutral detergent fiber, and nonstarch polysaccharides in relation to animal nutrition. J. Dairy Sci. 74:3583-3597.

Yáñez-Ruiz, D. R., A. Moumen, A. I. Martín-García and E. Molina-Alcaide. 2004. Ruminal fermentation and degradation patterns, protozoa population, and urinary purine derivatives excretion in goats and wethers fed diets based on two-stage olive cake: Effect of PEG supply. J. Anim. Sci. 82:2023-2032. 